\title{
Photophysical and photochemical properties of potential porphyrin and chlorin photosensitizers for PDT
}

\author{
Eduard Zenkevich "i,* Evgenii Sagun ", Valentin Knyukshto a. Alexander Shulga a, \\ Andrei Mironov ${ }^{b}$, Olga Efremova ${ }^{\text {b }}$, Raymond Bonnett ${ }^{c}$, S. Phinda Songca ", \\ Mohammed Kassem "

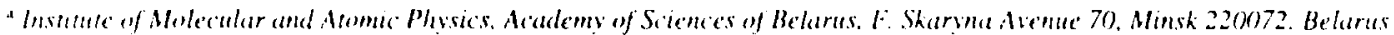

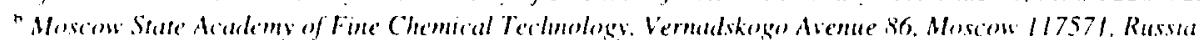

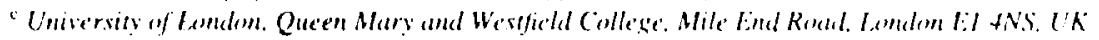

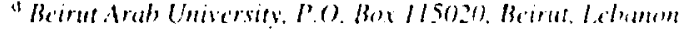

Received 21 June 1995: arcepted 11 September 1995

\begin{abstract}

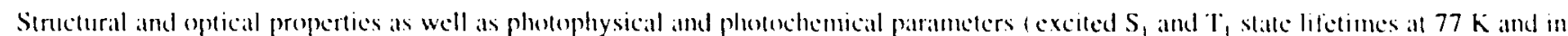

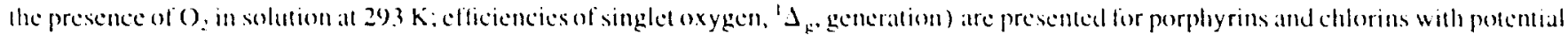

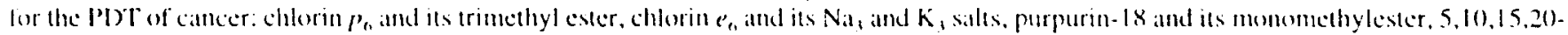

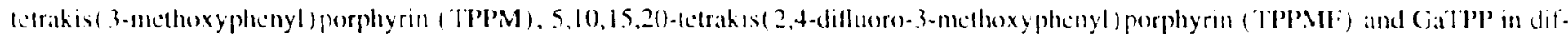

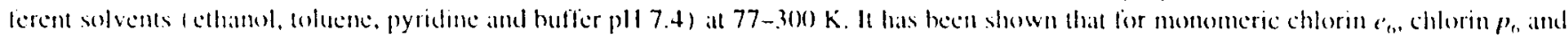

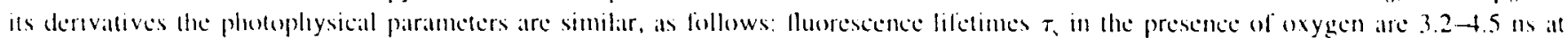

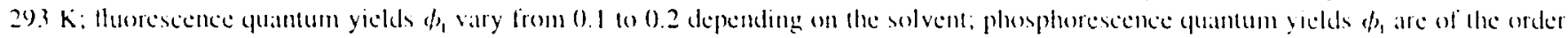

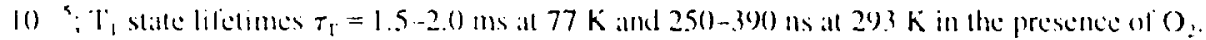

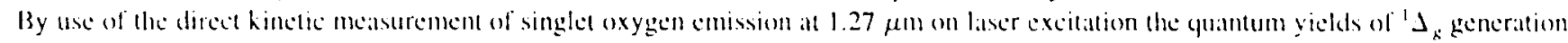

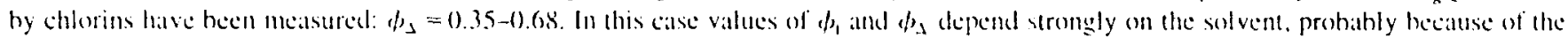

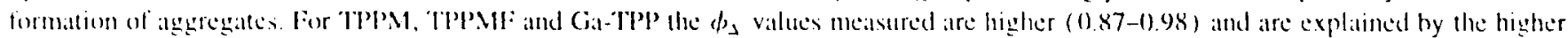
intersystcon crossing $S_{1} \rightarrow T_{1}$ (puantum yiluts.
\end{abstract}

Keyuards: Porphyrins; Chlorins: Photosensitiars: PI)T

\section{Introduction}

In the last decade there has heen increasing interest in the use of porphyrins and chlorins as photosensitizers for selective and effective destruction of animal and human malignant tumours $|1-1+|$. Photosensitization with different tetrapyrrole compounds has been shown to be an efficient process for the killing of cancerous and hacterial cells. It hats been suggested that singlet oxygen. produced by energy transfer from the sensitizer triplet stite to molecular oxygen, is the cytotoxic agent active in phototherapy in malignant tissues in vivo $\mid 9,15.161$

This developing medical application has stimulated a search for piotosensitizers which are more effective than the previously used hacmatoporphyrin derivatives and related

\footnotetext{
* Corresponding author.
}

compounds |3-7|. The new, "second-generation" photosensilizers must fulfil a number of crileria if they are to ade efliciently $17 \mid$. In addition to mecting the biological requirements, which appear to be best satisfied by a halance of hydrophobic and hydrophilic characteristics, the photosensitizer should have strong absorption in the red region of the visible spectrum. This criterion arises because, owing to lower scattering and to weak absorption by nalural chromophores. red light penetrates tissue much better than do the other parts of the visible spectrum. From a photophysical point of view, photosensitizers for this application also need to have a high intersystem crossing probability, leading to effective population of the triplet state. coupled with an efficient generation of singlet oxygen.

There is consequently considerable current interest in the synthesis and application of "new generation" photosensitizers based on various molecules containing a tetrapyrtole 
unit with increased red absorption, such as phthalocyanines [3.9], chlorins and purpurins [3-7,9-11], naphthaloporphyrins [17], and bacteriochlorins [11,18]. In this context, it should be noted that the choice and optimization of new tetrapyrrole-based photosensitizers is facilitated by the investigation of their photophysical and photochemical parameters in homogeneous solution as the first step. In addition, it is interesting to analyse the behaviour of their properties in solvents of different nature to control possible aggregation effects which can influence the photodynamic efficiency dramatically.

In the work reported here, optical. photophysical and photochemical parameters of purpurin-18 (P18) and chlorin $p_{6}$ $\left(\mathrm{Chl} p_{6}\right)$ and their derivatives as well as of some tetraphenylporphyrins are presented. The main emphasis is directed to the comparative analysis of the values obtained for new compounds in different solvents with the analogous parancters known for $\mathrm{Chl} e_{\mathrm{t}}$.

\section{Materials and methods}

\section{I. Materials}

Chlorophyll a has been isolated from plant materials by well-known methods $|19|$ and has heen converted clemically into PI8 and $\mathrm{Chl} c_{6}$ or $\mathrm{Chl} p_{0}$ and their derivatives with different substituents $[20\}$. The synthesis of the tetraphenylporphyrin derivatives 5, 10,15,20-tetrakis (3-mechoxyphenyl)porphyrin (TPPM) and 5,10,15,20-tecrakis (2,4difluoro-3-methoxyphenyl) porphyrin (TPPMF) hats been earried out using methods based on those described elsewhere [21]. The compounds have been characterized by the use of electronic and ${ }^{1} \mathrm{H}$ nuclear magnetic resonance spectroscopy and by mass spectronctry. The structural formulate of the compounds, and the abbreviations used here, are given in Fig. 1.

All solvents (ethanol, toluene, pyridine, isopropanol, diethyl ester (spectroseopic grade)) have been used without further purification. The experimental results have been obtained at ambient temperature or at $77 \mathrm{~K}$ in some calses.

\subsection{Spectral and kinetic measurements}

Electronic absorption spectra were recorded on Beckman 5270) and Specord M40 spectrophotometers. The photosensitizer fluorescence lifetime $\tau_{5}$ was measured using a PRA3000 pulse fluorometer operating in the single-photon counting mode.

Corrected fluorescence and phosphorescence spectra as well as fluorescence and phosphorescence excitation spectra were recorded on a laboratory spectral luminescent set-up, equipped with a personal computer. The operating spectral region was from $200 \mathrm{~nm}$ to $1100 \mathrm{~nm}$, and the exciting light sources were xenon and tungsten lamps or an argon laser. For better signal-to-noise ratio the experimental set-up was equipped with a thermocooling system for the photomultiplier (FEU-83 or FEU-100). The reproducability of the system is $5 \%$, the accuracy of emission quantum yield measurements is $5 \%-7 \%$ for $\phi_{t} \geqslant 0.1$, and the limit of emission quantum yield $\phi_{\mathrm{f}}$ measured is $10^{-5}$. The apparatus has been described in detail [22]. The emission quantum yields of the compounds under investigation were determined by the relative method [23]. Tetraphenylporphyrin in toluene $\left(\phi_{1}=0.09\right.$ at $\left.293 \mathrm{~K}\right)$ was used as a standard [ 43$]$. Quantum yields of phosphorescence were estimated by comparison with the fluorescence quantum yields of the same compound.

The kinetics of triplet-triplet absorption was studied on a standard laboratory flash photolysis set-up with a time resolution of $10^{-7}$ s $[24-26]$.

\subsection{Singlet oxygen laser fluorometry}

Spectra, kinctics and quantum yields of singlet oxygen emission were obtained using a laboratory experimental setup, described in detial in Refs. $|26-28|$. The simples were excited by the pulses of the second harmonic of an $\mathrm{AIG}: \mathrm{Nd}^{3}$ laser $(\lambda=532 \mathrm{~nm})$ or ruby latser $(\lambda=347 \mathrm{~nm})$ with a durattion of $20-30 \mathrm{~ns}$ and an energy density of $0.3-3.0 \mathrm{~mJ} \mathrm{~cm}$ : The probing of induced absorption was performed by a filatment lamp. The recording was carried out by a germanium photodiode or a photomultiplier tube and by a digital oscitteseope connected with a personal eomputer. The separate determination of quantum yicld d, of the sensitized producetion of singlet oxygen is not trivial.

Usually d, values are determined relative to each other or (1) sensitizers with a known yield. The decermination of the quantum yield of photosensitized formation of singlet oxygen $\left(\mathrm{O}_{2}\left({ }^{1} \Delta_{k}\right)\right)$ based on using standard compounds with welldocumented $\phi_{3}$ values in different solvents has heen described in detail $|29|$. In contrast with methods based on the photochemical oxidation of the substrate $|17,30|$ we used the direct spectral kinctic method for the measurement of singlet oxygen IR emission $(\lambda=1.27 \mu \mathrm{m})$. In this case uncertainties in the quantititive estimation of the role of singlet oxygen in the photochemical oxidation of the substrate are excluded. In this respect we consider that our method provides more accurate values of the quantum yields of singlet oxygen formation.

The main procedure for the delermination of the quantum yield $\psi_{s}$ of singlet oxygen formation may he presented as follows. When the compound under consideration and the standard were in the same solvent the value of $\phi_{\lambda}{ }^{x}$ for the compound was determined by the relative method, i.e. hy the conparison of the emission intensity of singlet oxygen, photosensitized by the compound under investigation (intensity $I_{s}$ ) and by the standard (intensity $I_{0}$ ):

$\phi_{د}{ }^{x}=\phi_{د}{ }^{0} \frac{l_{2}}{l_{0}} \frac{\beta_{0}}{\beta_{x}}$

where $\phi_{د}{ }^{0}$ is the quantum yield of singlet oxygen formation for the standard, and $\beta_{\mathrm{x}}=1-10^{\text {ti }}$ and $\beta_{0}=1-10^{-b_{1}^{t}}$ are the 


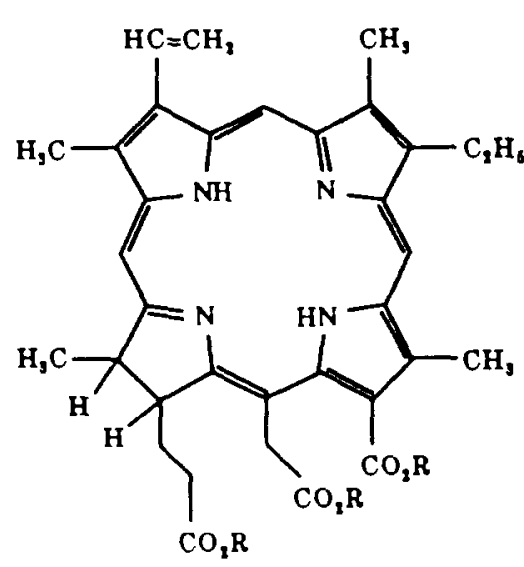

$\mathrm{Chl} \mathrm{e}_{6}: \mathrm{R}=\mathrm{H}$

$\mathrm{Chl} \mathrm{e}_{6} \mathrm{~K}_{3}: \mathrm{R}=\mathrm{K}$

$\mathrm{Chl} \mathrm{e}_{6} \mathrm{Na}_{3}: \mathrm{R}=\mathrm{Na}$

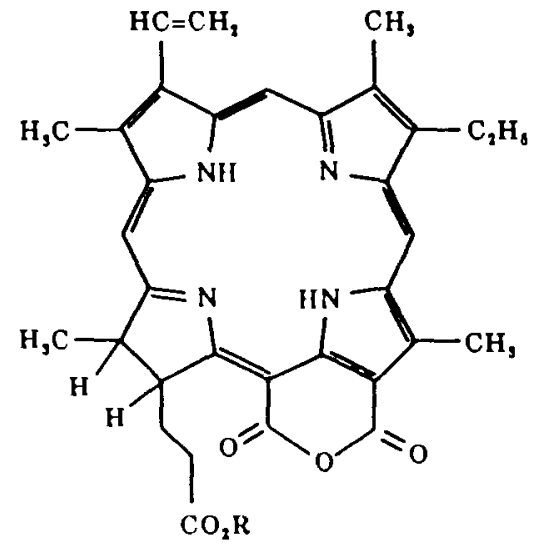

P18: $R=H$

P18-OMe: $\mathrm{R}=\mathrm{CH}_{3}$

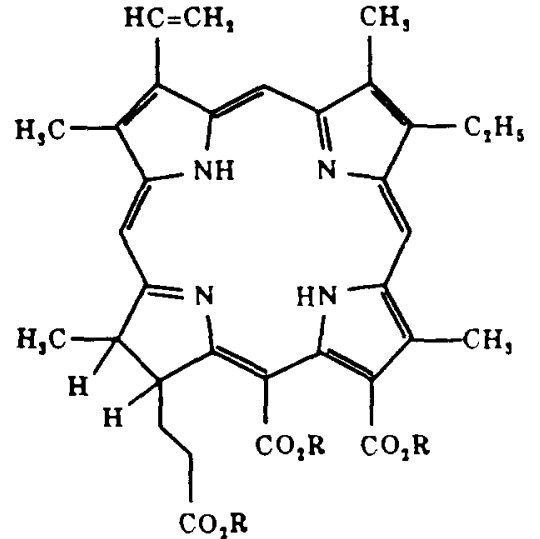

$\mathrm{Chl} \mathrm{p}_{6}: \mathrm{R}=\mathrm{H}$

$\mathrm{Chl} \mathrm{p}_{6}-(\mathrm{OMe})_{3}: \mathrm{R}=\mathrm{CH}_{3}$

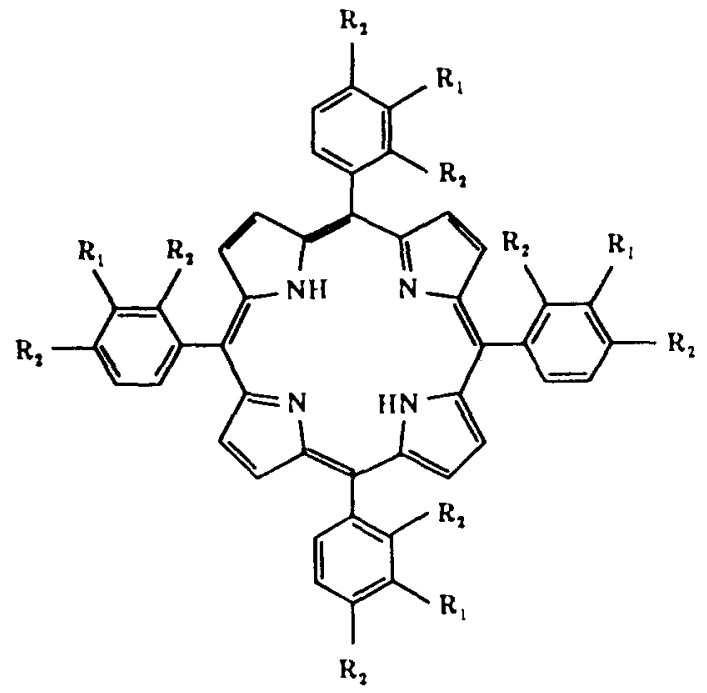

TPPM: $\mathrm{R}_{1}=\mathrm{OCH}_{3}, \mathrm{R}_{2}=\mathrm{H}$

TPPMF: $\mathrm{R}_{1}=\mathrm{OCH}_{3}, \mathrm{R}_{2}=\mathrm{F}$

Fig. 1. The structural formulate and acronyms of the purpurins, chlorins and etraphenylporphyrins studied here.

absorbed exciting light portions at excitation wavelength for the investigated and standard compounds respectively. $l_{\mathrm{x}}$ and $I_{6}$ values were obtained for no less than 30 laser pulses and then were averaged and extrapolated to the maximal pulse intensily.

Oxygen concentrations at ambient conditions in the solvents being used, and diclectric constant $\epsilon$ values were taken from Refs. \{26,31]. Various compounds were used as standards: (i) chlorophyll a $\left(\phi_{\Delta}{ }^{0}=0.6[26]\right)$ and octacthylporphyrin $\left(\phi_{\Delta}{ }^{0}=0.75[32]\right)$ in toluene solutions; (ii) methylene blue $\left(\phi_{\Delta}{ }^{0}=0.52\right.$ [33]) in ethanol; (iii) $\mathrm{Chl} e_{\mathrm{f}}$ $\left(\phi_{\Delta}{ }^{0}=0.74[34]\right)$ in pyridine. In all cases solution absorbance at the excitation wavelength was not higher than 0.2 at a path length of $10 \mathrm{~mm}$. The relative error of the $\phi_{s}{ }^{x}$ determination did not exceed 10\%-15\%.
The experimental set-up described permitted us to measure $\tau_{1}$ values for the compounds of interest in liquid solutions at $293 \mathrm{~K}$ in the presence of molecular oxygen as well. The corresponding values of singlet and triplet state quenching rate constants by molecular oxygen were calculated by using oxygen solubility data and physicochemical properties of solvents from Ref. [31]

The following formulac were used.

(i) For the rate constant $k_{\mathrm{T}}$ of triplet state quenching by molecular oxygen,

$k_{\mathrm{T}}=\frac{\left.\left(\tau_{\mathrm{T}}\right)^{-1}-\left(\tau_{\mathrm{r}}\right)^{0}\right)^{-1}}{10_{2} 1}$

where $\tau_{\mathrm{T}}{ }^{0}$ and $\tau_{\mathrm{T}}$ are triplet lifetimes of the compound under consideration in liquid solution in the absence and the pres- 
ence respectively of oxygen and $\left[\mathrm{O}_{2}\right]$ is the dissolved molecular oxygen concentration. As a rule in calculations of $k_{T}$ the value of $\left(\tau_{T}^{0}\right)^{-1}$ is neglected because of $\tau_{T}{ }^{0} \gg \tau_{T}$ (over 2-3 orders of magnitude).

(ii) For the rate constant $k_{\mathrm{s}}$ of singlet state quenching by molecular oxygen,

$k_{s}=\frac{\left(\tau_{s}\right)^{-1}-\left(\tau_{s}^{0}\right)^{-1}}{\left[O_{2}\right]}$

where $\tau_{s}^{0}$ and $\tau_{s}$ are singlet (fluorescent) lifetimes of the compound of interest in liquid solution in the absence and the presence respectively of oxygen. The relative error in the measurements is estimated to be $\pm 3 \%$ for $\tau_{\mathrm{s}} . \pm 5 \%$ for $\tau_{\mathrm{T}}$ and $\pm 10 \%-12 \%$ for $k_{\mathrm{s}}$ and $k_{\mathrm{T}}$.

\section{Results and discussion}

\subsection{Singlet and triplet parameters}

It is convenient to separate and discuss the results of our investigation by presenting them in three different parts: (i) purpurins, (ii) chlorins and (iii) tetraphenylporphyrins.

Figs. 2 and 3 show the absorption and corrected luninescence (fluorescence and phosphorescence) spectra of some representatives of these three groups of the compounds. The results of the study of their photophysical paranteters are summarized in Table 1.

\section{I.I. 'urpurins}

P18 in ethanol is characterized by a long-walvelength absorption band at $70(0) \mathrm{nm}$ which is attributed to a $\mathrm{Q}_{\mathbf{3}}(0,0)$ electronic transition [35]. The maximum of the Soret band is observed at $408 \mathrm{~nm}$ (sec Fïg. 2(a)). The ratio $A$ (Soret)/ $A\left(Q_{s}\right)=2.7$ reflects a situation which is typical for cetrapyrrole compounds with hydrogenated pyrrole rings $[36$. Table I shows that when the solvent is changed to toluene and pyridine the absorption spectra of P18 are red shifted by 4-7 $\mathrm{nm}$. In all solvents the weak vibronic structure of the first electronic $Q_{1}(0,0)$ transition is observed. In addition, a significant band at $547 \mathrm{~nm}$ manifests itself in contrast to the low intensity band for various "normal" chlorins in this region. According to our polarized fluorescence measurements for chlorins this band belongs to the second $Q_{v}(0,0)$ electronic transition [36]. The energy of this transition is almost independent of the substituents and the solvent and does not change with temperature decrease down $1077 \mathrm{~K}$.

The fluorescence spectrum of P18 (Fig. 2(a)) is roughly the mirror image of the long-wavelength region of the absorption spectrum and is characterized by weak vibrational structure. This means that, on excitation, the structural changes of P18 are quite small and the Frank-Condon principle, which determines the form of the absorption band, is applicable to the enission processes for this molecule.

The fluorescence quantum yicld $\phi_{i}$ of P18 is strongly dependent on the solvent, changing from 0.08 in ethanol to
D, Ium

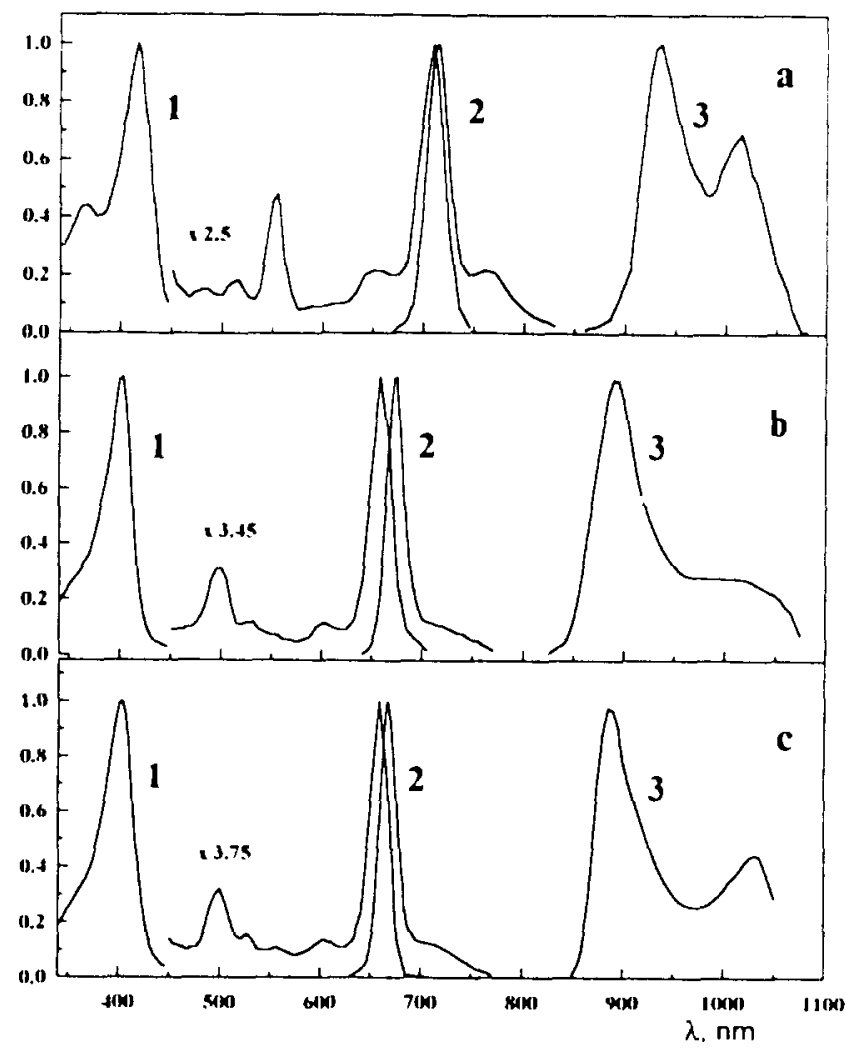

Fig. 2. Absorption (spectra $1 ; 29.3 \mathrm{~K}$ ) and corrected fluorescence (spectra 2; 29,3 $\mathrm{K}$ ) and phosphorescence (spectra 3:77 $\mathrm{K}$ ) spectra of (a) p/s in pyridine and (b) Chl $p_{n}$ and (c) Chl $e_{n}$ in ethanol

D), Itum

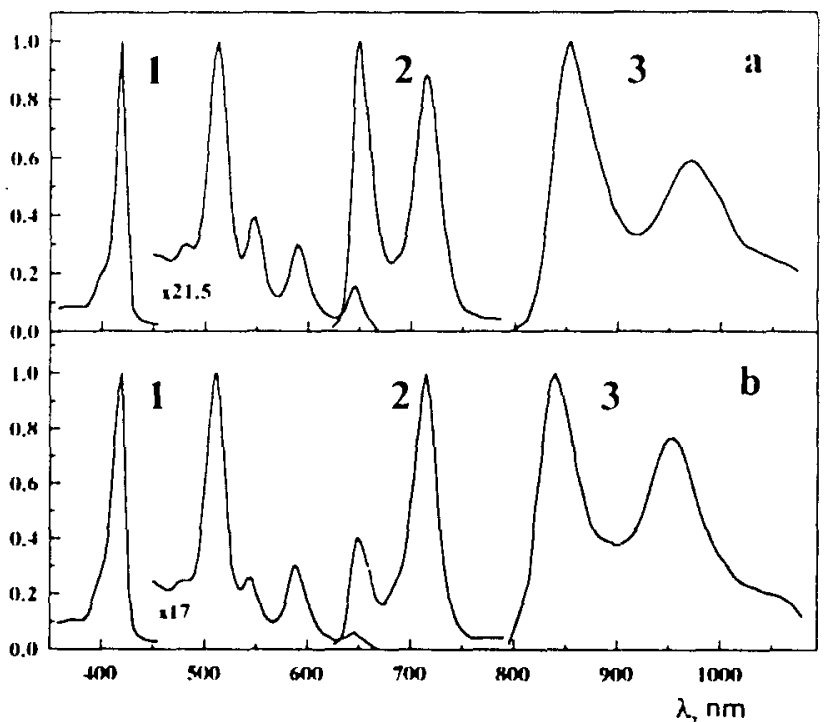

Fig. 3. Absorption (spectra 1: $293 \mathrm{~K}$ ) and correcied fluorescence ( spectra 2: $293 \mathrm{~K}$ ) and phosphorescence (spectra 3; $77 \mathrm{~K}$ ) spectra of (a) TPPM and (b) TPPMF in coluenc.

0.13 in pyridine. Nevertheless the fluoreseence lifetime $\tau_{s}$ remains practically constant in all solvents ( see Table 1). If one takes into account that the solubility of P18 in ethanol and toluene is significantly lower than that in pyridine, this 
Tuble I

Spectral luminescent parameters of chlorins. purpurins and tetraphenylporphyrin derivatives

\begin{tabular}{|c|c|c|c|c|c|c|c|c|c|c|}
\hline \multirow[t]{2}{*}{ Compound } & \multirow[t]{2}{*}{ Solvent } & \multicolumn{4}{|l|}{$\lambda_{\mathrm{max}}$} & \multirow{2}{*}{$\begin{array}{l}J E_{s_{1}-r_{1}} \\
\left|\mathrm{~cm}^{-1}\right|\end{array}$} & \multirow{2}{*}{$\begin{array}{l}b_{1} \mathrm{all} \\
29.3 \mathrm{~K}\end{array}$} & \multirow{2}{*}{$\begin{array}{l}\tau_{s} \text { at } \\
293 \mathrm{~K} \\
(\mathrm{~ns})\end{array}$} & \multirow{2}{*}{$\begin{array}{l}\phi_{1}, \mathrm{al} \\
77 \mathrm{~K} \\
\left(\times 10^{-5}\right)\end{array}$} & \multirow{2}{*}{$\begin{array}{l}T_{r} \mathrm{al} \\
77 \mathrm{~K} \\
(\mathrm{~ms})\end{array}$} \\
\hline & & $\begin{array}{l}\text { Absorbance } \\
\text { al } 293 \mathrm{~K}\end{array}$ & $\begin{array}{l}\text { Fluorescence } \\
\text { al } 293 \mathrm{~K}\end{array}$ & $\begin{array}{l}\text { Fluorescence } \\
\text { at } 77 \mathrm{~K}\end{array}$ & $\begin{array}{l}\text { Phosphorescence } \\
\text { at } 77 \mathrm{~K}\end{array}$ & & & & & \\
\hline \multirow{12}{*}{$\begin{array}{l}\text { Chl } p_{n}-M e_{1} \\
\text { Chl pn } \\
\text { Chl } e_{n} \\
\left(C h l e_{n}\right) N_{a_{1}} \\
\left(C h l e_{n}\right) K_{3} \\
C h l p_{n} \\
C h l e_{n} \\
\left(C h l e_{n}\right) N_{4} \\
\left(C h l e_{n}\right) K_{1} \\
\text { Pls }\end{array}$} & Toluene & 674 & 683 & 680 & 910 & 3720 & 0.19 & 3.8 & 0.75 & 1.1 \\
\hline & Ethanol & 664 & 672 & 670 & 898 & 3790 & 0.10 & 3.2 & 10 & 1.2 \\
\hline & Ethanol & 663 & 668 & $66-4$ & 886 & 3770 & 0.13 & 44 & 09 & 16 \\
\hline & Ethanol & 663 & 668 & 666 & 888 & 3750 & 0.15 & 43 & 12 & 14 \\
\hline & Ethanol & $66+$ & 670 & 665 & 900 & $30 \geq 0$ & 0.12 & +5 & 10 & 1.2 \\
\hline & Buffer. pH 7.4 & 6.56 & $66+1$ & & & & 0.17 & 3.3 & & \\
\hline & Buffer, pH 7.4 & 654 & 662 & & & & 0.18 & 37 & & \\
\hline & Buffer. pH 7.4 & 654 & 662 & & & & 0.22 & 3.7 & & \\
\hline & Bulfer, pH 7.4 & 656 & 662 & & & & 0.16 & 36 & & \\
\hline & Ethanol & 700 & 712 & & & & 0.04 & 24 & & \\
\hline & Toluent & 704 & 711 & & & & 0.08 & 2.6 & & \\
\hline & Pyridine & 707 & 714 & 712 & 930 & 3290 & 0.13 & 26 & 24 & 1.7 \\
\hline $\mathrm{P} \mid \mathrm{B}-\mathrm{Mc}$ & Toluent: & 702 & 710 & 709 & 917 & 3200 & 0.11 & $2 n$ & 2.8 & 18 \\
\hline $\mathrm{TPP}$ & Toluene & 645 & 653 & $6+5$ & 859 & 3860 & 0.00 & 107 & 67 & 58 \\
\hline TPPM & Toluene & $6+18$ & 652 & 045 & 8.58 & .3850 & 0.08 & 07 & 53 & 5.3 \\
\hline TPPMF: & Tolucist: & 645 & 648 & $6+6)$ & 840 & .3720 & 0.124 .5 & 100 & 5.5 & 7.2 \\
\hline
\end{tabular}

observation may be due to the partial aggregation of P' 18 in ethanol and toluenc at $293 \mathrm{~K}$. The same situation cannot he excluded in ethanol-elher mixtures used in Rei. $[37$ for the same compounds. It should be noted that for chlorins and chlorophyll-type molecules aggregation does not signilicantly change the spectral propertics of solutions in some cases but does lead to fluorescence quenching $|38,39|$. In nur casce at $77 \mathrm{~K}$ the fluoresecence of $\mathrm{P} / 8$ in ethanol and toluene decreatses by about 100 times. So, we stress that for Pl8 aggregation elfects must be taken into consideration when using different solvents.

In this regard, P/8-Me, having a higher solubility than PI8, is characterised by the same parameters of lluorescence in toluene as for P/8 in pyridine (sec Table 1). So, P18-Me may be considered as a potential sensitizer for PIDT purposes. Below we discuss its efficiency of singlet oxygen generation.

Finally, weak phosphorescence of $\mathrm{P}$ ls in pyridine and of Pl8-Me in toluenc has been observed at $77 \mathrm{~K}$ (sec Table 1 and Fig. 2(a)). The assignment of this emission to Pls or Pls-Me has been established by the coincidence of the phosphorescence excitation spectra with the absorption spectra of the corresponding compounds. Phosphoresecent data permitted us to estimate directly the energy of the triplet states.

\subsubsection{Chlorins:}

Comparison of figs. $2(a)$ and $2(b)$ shows that on moving from $\mathrm{Pls}$ (or Pl8-Me) to $\mathrm{Chl} p_{6}$ (or $\mathrm{Chl} p_{0}-(\mathrm{Mc})_{3}$ ) the Q. $(0,0)$ band in the absorption spectrum shifts to the shortwavelength region by $36 \mathrm{~nm}$. The vibrational structure of the first $Q,(0,0)$ electronic transition practically disappears. The intensity ratio $A$ (Soret) $/ A[Q,(0,0)]$ is approximately the same as for P18. However, the relative intensity of the Q, $(0,0)$ transition is drastically decreased and its position must be at $530 \mathrm{~nm}$, according to polarized fluoresence measurements on Chl $e_{i}[36]$.
The lluorescence spectrum of $\mathrm{Chl} p_{6}$, is essentially a single band (sec lige, 2(b)). As ome can see from Table I the fluorescence yuantum yicld of $\mathrm{Ch} / p_{t}$ in chanol is lower by 1.5-2.0 times in comparison with the andegens values measured for chlorins in different systems $134,36,40)$. As with P18 (sec Section 3.1.1) we believe that the decrease in $d_{t}$ in ethanol is connected with the partial aggregation of the pigment which is dec to the low solubility of this compound. For Chl pe--Me, which has a better solubility in celhanol and whene in comparison with $\mathrm{Chl} p_{\text {en }}$, the huorescence quantum yickd is near 0.2 (sec Tatble 1$)$.

A noteworthy feature of $\mathrm{Chl} p_{0}-\mathrm{Mc}_{3}$ is that its absorption $Q_{a}(0,0)$ band maximum in non-polar solvents $\left(\lambda_{\text {wax }}=674\right.$ non) coincides with a generation line of the Kr laser. This licature makes Chl $p_{t}-\mathrm{Me}_{3}$ an altractive possibility for Pl) when using laser excitation.

The phesphorescence paramelers of Chl $p_{0}-\mathrm{N}_{1}\left(\phi_{1}, T_{1}\right.$. sec Table 1) ats well as the $S,-T$, encrgy gap secm to be typical for chlorins 1361. Their energetic characteristics resemble the corresponding values of pheophysin $b|+1|$.

A spectral polarised study of $\mathrm{Ch}$ en and its energetics has been performed $\{36\}$ in which a glassy matrix of diethyl ether-petroleum ether $(1: 1)$ at $77 \mathrm{~K}$ has been used. In addition, the photodynamic action of this compound in several systems has been investigated $[3,34]$. Here we compare these data with present results (Table 1). The experimental data known for Chl e, (sec Fig. 2(c)) and observed for its derivatives in this investigation are comprehensively compared with spectral energetic characteristics and piotosensitization efficiency for $\mathrm{Ch} / \mathrm{p}_{\mathrm{s}}$ and $\mathrm{Chl} \mathrm{p}_{6}-\mathrm{Mc}_{3}$.

The experimental results given in Tahle 1 and in Fig. 2 lead to a number of conclusions. The spectral, energetic and kinetic characteristics of lumineseence of $\mathrm{Chl} e_{6}$, its salts $\left(\left(\mathrm{Chl} e_{6}\right) \mathrm{Na}_{3}\right.$ and $\left.\left(\mathrm{Chl} e_{6_{2}}\right) \mathrm{K}_{3}\right)$ and $\mathrm{Chl}_{p_{1}}$ and $\mathrm{Chl} p_{6}-\mathrm{Me}_{3}$ 
are rather similar. Structural changes (here, the introduction of ionic or ester peripheral substituents) have only a small influence on the photophysics of the compounds being investigated. This conclusion agrees with the conclusions presented in Ref. [35]. However, the nature of the solvent may influence the state of the pigment molecules. In some cases (especially, for ethanol) it lcads to aggregation effects. In other cases (for buffer solutions; sec Table 1) spectral shifts of absorption and lumineseence bands are observed without noticeable aggregation phenomena. The last observation for $\mathrm{Chl} e_{6}$ is mentioned in Refs. $[34,40,42]$ and is attributed to changes in dielectric constant in the medium surrounding the chromophore

\subsubsection{Tetraphenylporphyrin derivatives}

As will be shown helow. TPPM (with methoxy substitu(ion) and TPPMF ( with additional 2,4-difluoro substitution, Fig. 1) are of interest in PDT owing to their high efficiency of singlet oxygen formation. This led us to compare their spectral and lumineseence parameters, given in Fig. 3 and Table 1, with data for various halogen-substituted TPP compounds $|43-46|$. It must be noted that the spectral paramelers of TPPM practically coincide with these for TPP. At equal intensities of the fluorescence vibronic $Q(0,1)$ bands, the electronic $Q(0,0)$ band intensity for TPPM is 1.4 times lower than the corresponding band intensity for TPP. liurthermore, photophysical propertics of TIP'M $\left(\phi_{1}, \tau_{1}\right.$, and $\left.\tau_{p}\right) \mathrm{don}$ not differ considerably from the same values for TPP. So, the introduction of OMe groups al the meta position of the phenyl rings does not markedly influence the $\pi$ electronic system of the main chromophore. The changes in electronic spectral when moving from TPP' to TPPM are in a good agreement with our previous results [45], which have shown thall paramethoxy substitution, and fluoro substitution at the meta and ortho positions of the phenyl ring, resulted in a noticeable weakening of the intensity of the long-wavelength transition $\mathrm{Q}(0,0)$ band in the absorption spectrum. It should be noted that the weakening of the intensities of the $Q_{1}(0,0)$ and $\mathrm{Q}_{y}(0,0)$ bands in absorption ("phyllo-lype spectrum") has been observed previously $[43,45]$. The observed spectral features in this case have been attributed to the steric interaction of the halogen atom with the pyrrole ring. This leads, on the one hand, to increased difficulty in the rotation of the benzene rings around the $-\mathrm{C}-\mathrm{C}$ - bond and, on the other hand, (1) an increase in the energy of the highest occupied nolecular orbital a $\mathrm{l}_{\mathrm{u}}$ (for symmetry group $D_{4 \mathrm{~b}}$ ).

The same situation is observed in fluoro-substituted TPPMF (see Fig. 3(b)) where the intensity of the longwavelength $Q(0,0)$ band decreases almost fourfold relative to TPP. As a result, the fluorescence quantum yield of TPPMF is half that for TPP at the same fluorescence probability. We suppose that the decrease in fluorescence efficiency is due to the absolute decrease in the $Q(0,0)$ transition intensity.

The experimental results obtained for TPPMF show that the incorporation of fluorine atoms at para and ortho posi- tions of the phenyl ring does not cause a change in the intersystem crossing probabilities. However, it has been shown that para- $\mathrm{Cl}$ substitution in TPP reduces the phosphorescence lifetime and increases the phosphorescence quantum vield [45]. Thus in the case of TPPMF one should assume that the phenyl rings are rotated by a large angle (about $60^{\circ}$ ) relative to the $\pi$ electronic macrocycle and do not take an effective part in conjugation.

\subsection{Interaction with molecular ongen}

\subsubsection{Chlorins and their derivatives}

Table 2 summarizes the main results obtained for the compounds under consideration when interacting with molecular oxygen. The rate constants $k_{\mathrm{s}}$ and $k_{\mathrm{T}}$ of singlet and triplet state quenching by molecular oxygen for $\mathrm{Chl} p_{n}$ in ethanol are practically the salme as the corresponding values for $\mathrm{Chl}_{1}$ $e_{e}$. It should be mentioned that the rate constants $k$, for these compounds are practically the same as the diffusionally controlled values of $k_{\text {dit }}$ in this solvent. At the same time the experimental ratio $\beta=k_{\mathrm{r}} / k_{\mathrm{s}}=0.22$ for these two compounds in ethanol is noticeably higher than the spin statistical factor $g_{1}=1 / 9$, taking into account the spin states of sensitirer molecule and molecular oxygen. The last fact may be explained by the inclusion, in the quenching of $T$ states by molecular oxygen, of the other spiti states of the collision complex $\left(k_{r}\right)$ which are not connected with singlet oxygen generation. For instance, the following process may occur:

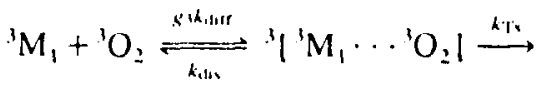

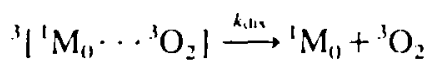

where $g_{3}=1 / 3$ is the spin statistical facetor, $k_{\text {thl }}$ is the diffusion rate constant, and $k_{\mathrm{d} 1}$ is the rate constimt of complex dissociation.

However, the high values of the singlet oxygen gencration quantum yield as well as the observed non-dependence of $\phi_{\lambda}$ and the rate constant $k_{\mathrm{r}}$ of triplet state quenching on the medium polarity for $\mathrm{Chl} e_{0}$ (ethanol, coluene; see Table 2) do not support such a possibility. The same situation has been observed for chlorophyll-lype molecules [26] and has been explained as a result of the increasing probability $k_{x}$ of the spin-forbidden transition between triplet and singlet states of the collision complex:

$$
{ }^{3}\left[{ }^{3} \mathrm{M}_{1} \cdots{ }^{3} \mathrm{O}_{2}\left|\stackrel{k_{2}}{\longrightarrow}{ }^{1}\right|{ }^{1} \mathrm{M}_{6} \cdots{ }^{1} \mathrm{O}_{2}\left({ }^{1} \Delta_{k}\right)\right]
$$

It should be stressed that such a transition is spin forbidden and is not generally observed for aromatic molecules. The energy gap between the sensitizer $T_{1}$ state and the oxygen $' \Delta_{\mathrm{g}}$ state is not so large for chlorophyll-type molecules. Hence, this transition is characterized by a higher value of the Franck-Condon factor which leads to an increase in the non-radiative transition probability. Moreover, in this case the existence of a low-lying charge transfer state, which may also influence $k_{\mathrm{x}}$, is not excluded. On salt formation (from $\mathrm{Chl} e_{6}$ to $\left(\mathrm{Chl} e_{6}\right) \mathrm{K}_{3}$ or $\left.\left(\mathrm{Chl} e_{6}\right) \mathrm{Na}_{3}\right)$ we do not obscrve 
Table 2

Photophysical properties and parameters of interaction of the compounds with molecular oxygen

\begin{tabular}{|c|c|c|c|c|c|c|}
\hline Compound & Solvent & $\begin{array}{l}T_{T} \\
\text { (ns) }\end{array}$ & $\begin{array}{l}k_{\mathrm{r}} \times 10^{-9} \\
\left(M^{-1} \mathrm{~s}^{-1}\right)\end{array}$ & $\begin{array}{l}k_{3} \times 10^{-0} \\
\left(\mathrm{~N}^{-1} s^{-1}\right)\end{array}$ & $\beta=\frac{k_{r}}{k_{1}}$ & $\phi_{1}$ \\
\hline \multirow[t]{2}{*}{$\mathrm{Chl} e_{n}$} & Ethanol & 290 & 2.1 & \multirow[t]{3}{*}{9.4} & \multirow[t]{3}{*}{0.22} & $0.65 \pm 0.06$ \\
\hline & Toluene & 255 & 2.2 & & & $0.61 \pm 0.06$ \\
\hline$\left(\mathrm{Chl} e_{n}\right) \mathrm{Na}_{4}$ & Ethanol & 305 & 2.0 & & & $0.68 \pm 0.06$ \\
\hline$\left(\mathrm{Chl} e_{n}\right) K_{1}$ & Ethanol & 260 & 2.3 & 9.3 & 0.24 & $0.68 \pm 0.06$ \\
\hline \multirow[t]{2}{*}{$\mathrm{Chl} p_{n}$} & Ethanol & \multirow[t]{5}{*}{255} & \multirow[t]{5}{*}{$2 .+$} & \multirow[t]{5}{*}{9.9} & \multirow[t]{5}{*}{0.24} & $0.60 \pm 0.06$ \\
\hline & Pyridine & & & & & $0.35 \pm 0.05$ \\
\hline \multirow{3}{*}{$\mathrm{Chl} p_{0}-\mathrm{Me}_{3}$} & Ethanol & & & & & $0.69 \pm 0.06$ \\
\hline & Toluene & & & & & $0.65 \pm 0.06$ \\
\hline & Pyridine & & & & & $0.79 \pm 0.07$ \\
\hline \multirow[t]{3}{*}{ P18 } & Ethanol & 195 & 3.1 & & & $0.45 \pm 0.10$ \\
\hline & Toluene & \multirow[t]{5}{*}{250} & \multirow[t]{5}{*}{2.2} & & & $0.70 \pm 0.07$ \\
\hline & Pyridine & & & & & $075 \pm 0.07$ \\
\hline \multirow[t]{3}{*}{$\mathrm{P} 18-\mathrm{ML}$} & Ethanol & & & & & $0.55 \pm 0.10$ \\
\hline & Toluene & & & & & $0.73 \pm 0.07$ \\
\hline & Pyndine & & & & & $0.80 \pm 0.08$ \\
\hline TPP & Toluene * & \multirow[t]{3}{*}{400} & \multirow[t]{3}{*}{14} & \multirow[t]{5}{*}{110} & \multirow[t]{5}{*}{0.127} & $0.68 \pm 0.06$ \\
\hline \multirow[t]{4}{*}{ GaTPP } & Ethanol & & & & & $095 \pm 0.05$ \\
\hline & Pyridine & & & & & $0.85 \pm 0.08$ \\
\hline & Toluene" & 545 & 1.05 & & & $0.85 \pm 0.08$ \\
\hline & Acetonitrile" & 685 & 09 & & & $0.98 \pm 0.02$ \\
\hline TPPM & Toluene & 300 & 185 & 15.8 & 0.117 & $0.87 \pm 0.08$ \\
\hline TPPMF: & Toluene & 390 & $1+$ & 12.7 & 0.112 & $0 \times 8 \pm 0.08$ \\
\hline
\end{tabular}

- Taken from Refs. 125.321.

"These values have been determined hy E.1. Sagun and B.M. Dzhagarov.

noticeable changes in rate constants $k_{s}$ and $k_{\mathrm{p}}$, but only a slight increase (about $5 \%$ ) in the singlet oxygen generation quantum yicld. A small increase in the ratio $\beta=0.24$ for ( $C h 1$ $\left.e_{6}\right) K_{1}$ in this casc may be connected with the lowering of the energy of its T, level. The position of the phosphorescence maximum of this compound and the shortening of its $\tau_{1}$ ( sec Table 1 ) support such an explanation.

It must be noted that $\mathrm{Chl}_{\mathrm{p}}$ is characterized by a lower solubility in eomparison with $\mathrm{Chl} e_{e}$ in the solvents being used. For instance, $\mathrm{Ch} / p_{b}$ hass a small solubility in pyridine and it is scarcely soluble in toluene. However, in ethanol, where its solubility is relatively high, the photophysical parameters of this compound $\left(k_{s}, k_{r}, \phi_{\lambda}\right)$ are practically the same as the analogous parameters of Chl $e_{6}$ ( see Table 2 ). In this connection, the low value of the singlet oxygen generation quantum yicld for $\mathrm{Chl} p_{0}$ in pyridine $\left(\phi_{\lambda}=0.35 \pm 0.05\right)$ may be attributed to its low solubility and to aggregation effects.

In contrast to $\mathrm{Chl} p_{0}$, the ester $\mathrm{Chl} p_{0}-\mathrm{Mc}_{3}$ has a rather good solubility in all the solvents used and is characterized by higher $\phi_{2}$ values in corresponding media compared with $\mathrm{Chl} e_{0}$ and $\mathrm{Chl} p_{0}$ (by approximately $5 \%-10 \%$ ). For the purposes of singlet oxygen generation, $\mathrm{Chl} p_{0}-\mathrm{Mc}_{3}$ exhibits the best activity of this group of compounds.

\subsubsection{Purpurins}

As mentioned above the use of a long-wavelength band of the sensitizer is desirable because of the better lissue penetration of exciting light in wivo. Purpurin and its analogues may be considered as promising candidates in this respect. The bathochromic shift of the long-wavelength absorption band of PI8 and Pl8-Me (sec Table 1 ) in comparison with (h) $e_{0}$ reveals a noticeable lowering of the energies of their $S_{1}$ levels. In accordance with well-known photophysical correlations one would expect the simulaneous lowering of the $T_{1}$ levels and an increase in the probabilities of non-radiative $T_{1} \rightarrow S_{0}$ transitions resulting in a diminishing of quantum efficiency of singlet oxygen generation by these molecules.

Nevertheless Table 1 shows that the triplet lifelimes $\tau_{p}$ of P18 and P18-Me at $77 \mathrm{~K}\left(\tau_{1}=1.8 \times 10^{-3} \mathrm{~s}\right)$ are similar (o) the corresponding values for chlorins. This means that, on the one hand, the purpurins being investigated are not characterized by higher values of the non-radiative intersystem crossing $T_{1} \rightarrow S_{0}$ probability $k_{4}$. On the other hand, the long triplet lifetimes of these compounds facilitate the high probability of diffusional collision of P18 and P18-Me triplet molecules with oxygen saturated solutions. It must be noted that in liquid solution the small value for P18 $\tau_{r}$ and the high rate constant $k_{r}$ (sec Table 2) points to the high quenching efficiency of the compound by nolecular oxygen. In addition. the high values of quantum yields of singlet oxygen generalion by $\mathrm{P} 18$ in pyridine and toluene resemble the same sensitizers for $\mathrm{Chl} p_{6}-\mathrm{Me}_{3}$. Table 2 shows also that, under the same conditions, the reduced derivative of P18, P18-Me, exhibits a slightly higher (by $5 \%-6 \%$ ) value of $\phi_{2}$, and from this point of vicw P18-Me might be a better potential photosensitizer for cancer therapy than PI8. However, in ethanol we obtained lower values of the singlet oxygen generation 
quantum yicld $\left(\sigma_{3}=0.45-0.55\right)$ for P18 and P18-Mc. As discussed earlier. this effect may be due to the low solubility of these compounds in solution and consequent aggregation phenomena.

\subsubsection{Tetrapheny/porphyrin derivatives}

Let us consider the third group of the compounds being investigated (TPPM, and GaTPP). Various derivatives of TPP have been investigated and used widely as photosensitizers of singlet oxygen $[47-49]$. It has been shown that the photophysical properties and the efficiency of singlet oxygen depletion depend strongly on the nature of the eentral metal ion and the character of the peripheral substituents. For instance, for halogen-substituted TPP derivatives (part- $F_{1}$. $-\mathrm{Cl}_{3},-\mathrm{Br}_{4}$ and $\left.-\mathrm{I}_{4}\right)[32]$ increasing the atomic number $(Z)$ of the halogen atom the $\phi_{2}$ value becones larger, being $0.65 \pm 0.06$ for TPP(parct-F $\left.F_{4}\right)$ up to $0.97 \pm 0.03$ for TPP (para- $\left.I_{4}\right)$. This effect is explained by the strengthening of spin-orbital inceraction according (o) the heavy atom perturbation in the sensitizer molecule. In addition, it has been established that d, depends not only on the $Z$ value but is sensitive (o) the position of the halogen in the phenyl ring relative to $\pi$ generated system of porphyrin molecule, being 0.71 for TPP(pora-Cl $)_{4}, 0.82$ for TPP (mete-Cl) $)_{4}$ and 0.84 for TPP(ortho-Cl). Moreover, in the same group of compounds the $k_{r}$ values decrease. This eflect has been related to the increase in porphyrin oxidation potential and the decrease in the contribution of donor-alcecptor interactions in the quenching process. Finally, it has heen found that incorporating the electron donor amino group ( $\mathrm{NI}_{2}$ ) in the meso position of the porphyrin molecule increases $k_{r}$ and $\phi_{2}$ values whereas the electron acceptor meso-nitro group $\left(\mathrm{NO}_{2}\right)$ reduces singlet oxygen gencration quantum yields $[32 \mid$.

Taking into account the results outlined above we can analyse the experimental data summarized in Table 2 . It is seen that the incorporation of the electron donor methoxy group $\mathrm{OCH}_{3}$ in the meta positions of the phenyl rings of the TPP molecule (in the calse of TPPM) results in the increase in rate constants $k_{\text {, and }} k_{r}$ as well as increalsing the $\phi_{3}$ value. Incorporation of the electron acceptor Fattoms in TPPM (giving TPPMF) is accompanied by a small decrease in the $k$, and $k_{r}$ whereas the $\phi_{\perp}$ value searcely changes. The same influence of $F$ atoms on $\phi_{1}$ values has been noted earlier [32]. This effect may be related to a relatively small heavy atom perturbation ( $Z=9$ for $F$ atom ). For the compounds of interest the observed dependence of quenching rate constints on the sensitizer oxidation potential may be considered as supporting a quenching inechanism due to a donor-acecptor interaction [50].

Table I shows that the incorporation of the electron-donating $-\mathrm{OCH}_{3}$ group into TPP (to give TPPM) results in the shortening of $\tau_{p}$ at $77 \mathrm{~K}$, whereas the incorporation of electron-altracting F aloms (to give to TPPMF) leads to longer $\tau_{\mathrm{p}}$ values again. The analogous situation has been observed earlier [29] and has been connected with the change in locil electron density on the central nitrogen atoms and the corresponding change in the $\mathrm{N}-\mathrm{H}$ vibrations.

GaTPP is characterized by high solubility and appreciable photochemical stability. The experimental results show that, in accordance with "the heavy atom effect", GaTPP has a relatively high quancun yield of ' $\Delta_{\mathrm{g}}$ generation $\left(\phi_{3}=0.85-\right.$ 0.98 ) in all solvents being used. This compound is an effictive sensitizer of singlet oxygen.

The direct estimation shows that for TPPM and TPPMF

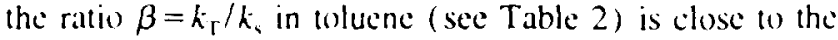
spin statistical factor $g_{1}=1 / 9$. This fact. logether with the high values of $\phi_{3}$. indicates that the quenching of the triplet states of these compounds oceurs by the mechanism of singlet oxygen generation exclusively:

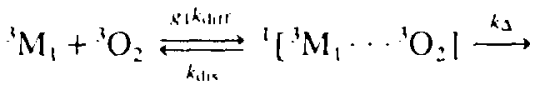

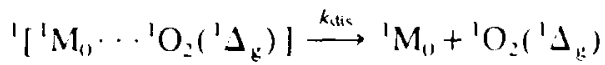

\section{Conclusions}

The results of the comprehensive study of optical and photophysical parameters of the compounds under consideration as well as the detailed mechanisms of their interaction with molccular oxygen lead to the following conclusions.

(1) The guantum yield of the photosensitized generation of singlet oxygen by $\mathrm{Chl} p$, in cthanol coincides with the same parameter for Chl $e_{0}$.

(2) The singlet oxygen formation quantum yicld t, for chlorins and purpurins does not appear to depend markedly on medium polarity. The decrease in $\phi_{1}$ and $\phi_{2}$ values in some cases is presumed to be due to the low solubility of the compounds and corresponding aggregation effects.

(3) Esters of Chl $p_{0}$ and $\mathrm{P} / 8$ (Chl $p_{6}-\mathrm{Me}_{3}$ and $\mathrm{P} / 8-\mathrm{Me}$ respectively), having higher solubility in comparison with the parent acids, are characterized by slightly higher $\phi_{3}$ values (by about $5 \%-10 \%$ ). This property, combined with strong absorption bands in the red region $(660-700$ nin), makes these molecules potential candidates for biological photosensitization.

(4) For TPPM, TPPMF and GaTPP photophysical properties depend strongly on the nature of substituents, and these compounds are highly effective photosensitizers of molecular oxygen in solution.

\section{Acknowledgements}

This research was supported by the INTAS Project (Grant 93-2810), the National Foundation for Basic Research of Belarus (Grant Ph5-111), the International Science Foundation (Grants RW 1000 and MD 2300), and the UN Education and Training Programme for Southern Africa. 
The authors would like to thank S.M. Bachilo and N.N. Kruk for the measurements described in the first paragraph of Section 2.3.

\section{References}

(1) L.I. Grossweiner, A. Blum and G.C. Goyal, Photophysics and photochemistry of hematoporphyrin derivative and uroporphyrin I, in D. Kessel (ed.), Methods in Porphyrin Photosensitization. Advances in Experimental Medicine and Biology. Vol. 193. 1985. pp. 181-192

[2] J. Moan, Porphyrin photosensitization and phototherapy. Photochem. Photobiol. A3 (1986) 681-690.

[3] M. Kreimer-Birnbaum, Modified porphyrins, chlorins, phthalocyanines and purpurines: second generation photosensitizers for photodynamic therapy, Semin. Hemutol., 26 (1989) 157-173.

[4] G.A. Kostenich, G.P. Gurinovich, G.A. Kochubeev, M.V Sarzhevskaya and A.A. Frolov. Photodynamic effect of chlorin $e_{n}$ on experimental tumours, in I.G. Zhakov (ed.). Actual Problems of Oncology and Medicine Radiology. Nauka i Technika, Minsk, 1986. pp. $168-173$

[5] J.S. Nelson, W.G. Roterts and M.W. Berns, In vivo studies on the utilization of mono-l-aspartyl chlorin (NPen $)$ for photodynamic therapy. Cancer Re's., 47 (1987) $4681-4685$.

[6| A.A. Frolov. E.I. Zenkevich. G.P. Gurinovich and G.A. Kochutherv. Chlorin $e_{n}$-liposome interaction. Investigation by the methods of fluorescence spectroscopy and inductive resonance energy transfer, $J$ Photeche'm. Photobiol. B: Biol. 7 (1999) 4.3-56,

[7| R. Bonnett and M. Berenbaum, Porphyrins as photosensitizers, (ila Foundation Svmp.. 146 (1989) 40-59

[8] A.F. Mironov. Photosensitizers hased on hemaloporphyrin for diagnostics and therapy of cancer decreatses, in Alstrats lint. Comf. om Coherent and Nenline'ar Optics, Minsk, 1988, 6-7.

[9]S. Kimel. B.J. Tromberg. W.G. Rotherts and M.W. Berns. Singlet oxygen generation of porphyrins. chlorins and phthallocyanines, Photeshem. Photetriol. 50 (1989) 175-18.3.

[10] R.K. Pandey, F.U. Shiau. K. Ramachandran, T.J. Dougheny and K.M. Sunth. Long wavelength photosensitizers related to chlorins and hacteriochloriss for use in photedynamic therapy. J. Chem. Sin: Perkin Trans. I. (1942) 1377-1385.

[11] K.R. Adams, M.C. Bcrenbaum, R. Bonnett, A.N. Nizhnik, A. Salgado and M.A. Valles. Second generation tumour photosensitizers: the synthesis and biological activity of octaalkyl chlorins and bacteriochlorins with graded amphiphilic character. J. Chem. Soc. Perkin Trans. I. (1992) 1465-1470

[12] R. Bonnets and M.C. Berenbaum, in D. Kessel and T.J. Dougherny (eds.), Porphyrin Phososensitizalion, Plenum, New York, 1983. pp 241-250.

113] G. Jori. R. Reddi, L. Tornio and F. Galzavara. Factors governing the thechanism and efficiency of porphyrin-sensitized photooxidations in homogencous solutions and organized media. in D. Kessel and T.J. Dougherty (eds.). Porphyrin Photosensitization. Plenum, New York. 1983, pp. 193-212

[14] J.D. Spikes. Photosensitizing properties of porphyrins in model cell systems, in A. Andreoni and R. Cubeddu (eds.). Porphyrins in Tumour Phototherupy. Plenum, New York, 1984. pp. 51-60.

[15] T.J. Dougherty. C.J. Gomer and K.R. Weishaupt, Energetics and efficiency of photoctivation of murine tumour cells containing hematoporphyrin. Cancer Res.. 36 ( 1976) 2330-2333.

[16] G.P. Gurinovich. I.G. Zhakov, G.A. Kostenich, G.A. Kochubectv. M.V Sarzhevskaya and A.A. Frolov. Singlet oxygen and cancer phototherapy, Vestm. Akad. Med. Nauk SSSR. 12 (1987) 24-30.

[17] L. Roitman, B. Ehrenberg and N. Kobayashi, Spectral properties and absolute determination of singlet oxygen production yicld by naphthaloporphyrins, J. Photochem. Photobiol. A: Chem., 77 (1994) $23-28$
[18] J.J. Schuitmaker, H.L.L.M. Van Leengoed, N Van der Veen, T.M.A.R. Dubbelman and W.M. Star. Laser-induced in vivo fluorescence of bacteriochlorin a. Lusers Med. Sci.. 8 ( 1993) 39-12

[19] O.N. Koifman. K.A. Askarov, B.D. Berezin and N.S Enikolopyan. Porphyrin natural sources. Methods of separation and modification of natural porphyrins, in N.S. Enikolopyan (ed.). Porphyrins: Structure, Properties, Synthesis. Nauka. Moscow. 1985. pp. 178-180

[20] A.S. Brandis, A.N. Kozyrev and A.F. Mironov, Synthesis and study of chlorin and porphyrin dimers with ether linkage. Tetruhedron. 48 (1992) 6+85-6+44.

[21] R. Bonnett and S.P. Songca. New fluorinated photosensitizers based on tetrakis (hydroxyphenyl)porphyrins, Proc. Sic. Phore-Om. Instrum. Eng. 2325 (1994) 150-154.

[22] A.P. Losev, V.N. Knyukshto and G.V. Gyulhandanyan. Investigation of photodynamic action primary stages by phosphorescence of sensitizer Pd-porphin complexed with proteins. Zh. Prtkl. Speksrosk. 58 (1993) $11+125$.

[23] C.A. Parker, Photoluminescence of Solutions. Elsevier. Amsterdam. 1968

[24] G.P. Gurinovich. E.I. Zenkevich. E.I. Sagun and A.M. Shulga. Spectral-luminescent properties and energetics of covalently honded dimers of various porphyrins, Ope. Spektresk.. $56(19 \times 4) 637-641$.

[25] B M. Dehagarov. E.I. Sagun. S.L. Bondarev and G.P. Gurinovich. The influence of molecular structure on processes of nonradiative deactivation of porphyrin lowest excited states, Bioficikat. 22 (1977) $56,5-571$

[26] B.M. Dshagarov, E.1. Sagun, V.A. Gantha and GP. Gurinovich. Mechanism of triplet state yuenching of chlorophyll and related compounds by molecular oxygen, Khim. Fi. 6 6 (1957) 919-928.

[27| S.L. Bondarev. S.M. Bachilo and I I Ivanov. Tince-resolved laser study of the transiemt absorption and conductivity on iodore-doped $\beta$ -

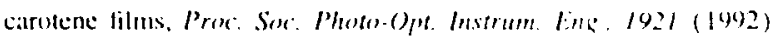
$158-166$

[28] S.L. Bondatev and S.M. Bachilo, Intersystem crossing $S_{1} \rightarrow T_{1}$ and spectral-kinetic properties of triplet states of er-yuatertiophene in solutions, Zh. Prikl. Spektrosk., 60(1994) 292-297.

[29| E:I. Sigun, Derefor Ilabil. Thesis. Minsk, 1994

130) H1.11 Wasserman and R.W. Murray (eds.), Singlet Orvgen, Organic Chemistry, Vol 40, Acidemic Press. New York, 19-9)

[31] S L. Murov, I Carmichatel and G.L. Hug, Homdlowok of Photo. chemisery, Dekker, New York, 1993.

[32] V.A. Giun ha, G.P. Gurinovich, B.M Dehagarov, G.D. Egorova, E.I Sagun and A M. Shulga, Influence of the molecular structure on the quenching of triplet states of porphyrins by molecular oxygen. $Z$ th. Prikl. Spekerosk., $50(1989)+402-406$.

133/ C. Tanielian. L. Golder and C. Wolff, Production and yuenching of singlet oxygen hy the sensitizer in dye-sensitized photo-oxygenations. J. Photoctiem. $25(1984) 117-125$.

[34] G.A. Kochubeev, A.A. Frolov and G.P. Gurinovich, Chlorin e", Spectral-energetic charateteristics and generation of singlet molecular oxygen in the same homogeneous and heterogeneous systems. Khim. Fiz..8(1989) 1184-1190

[35] V.A. Kusmitskit, K.N. Solov'ev and M.P. Tzvirko, Spectroscopy and quantum chemistry of porphyrins, in I'orphyrins: Spectroscopy, lelectrochemistry. Applications. Nauka. Mosicow. 1987. pp. 7-126

[36] S.S. Dvomikov. V.N. Knyukshto and K.N. Solovev. Spectral polarized investigation of luminescence of mesopheophytin a. chlorin $e_{n}$ and their inctallocomplexes. Opt. Spektrosk. 57 (1981) 285-292.

[37] A.P. Loser and N.D. Kochubeeva, Chemical structure and photophysical properties of photodynamic action sensitizer. Khim. Fi... $9(1990) 616-622$.

[38] M.J. Juen, L.L Shipman. J.J. Katz and J.C. Hindman. Concentration quenching of fluoreseence from chlorophyll $a$, pheophytin $a$. pyropheophytin a and their covalently-linked pairs. Photochem. Photobiol.. 32 (1980) 281-296. 
[39] E.I. Zenkevich, M.V. Sarzhevskay , T.V. Vitovizeva and G.A Kochubetev, Laws of aggregation and electronic excitation energy transfer in associates of pheophycin and its meso derivatives. Mol. Biol. 15 (1981) 145-153.

[40] E.1. Zenkevich, G.A. Kochubeev and K.I. Salochiddinov, Spectralluminescent and energy characteristics of water-soluble chlorin pigment bound to a protein carrier, Zh. Prikl. Spektrosk., 29 (1978) $1198-1203$.

[41] S.S. Dvornikov, V.N. Knyukshto, K.N. Solov'ev and M.P. Tzvirko, Phosphorescence of chlorophylls $a$ and $b$ and their pheophytins. Opt. Spektrosk., 46 (1979) 689-695.

[42] G.A. Kochubeev, A.A. Frolov, E.l. Zenkevich, G.P. Gurinovich. Chlorin $e_{5}$ complexation with serum human and bovine albumins, $M o l$. Biol., 22 (1988) 968-975.

[43] G.D. Egorova, V.N. Knyukshto, K.N. Solov'ev and M.P. Tsvirko, Intramolecular spin-orbital perturbations in ortho- and meta-halogen derivatives of tetraphenylporphyrin. Opt. Spektrosk. \$8 (1980) 11011109.

[44] K.N. Solov'ev. M.P. Tzvirko. A.T. Graduyshko and D.T. Kozhich. Halogen derivalives of tetraphenylporphyrin, Opt. Spektrosk. 33 (1972) 871-878.
[45] E.A. Borisevich. G.D. Egorova. V.N. Knyukshto and K.N. Solov 'ev, Photophysical processes in molecules of para-halogen derivatives of tetraphenylporphyrin and tetraphenylchlorin, Opt. Spektrosk., 63 (1987) 61-65.

[46] E.A. Borisevich, V.N. Knyukshto, G.D. Egorova and K.N. Solov'ev, Inner effect of heavy metal in metallocomplexes of para-bromo substituted tetraphenylporphin. Opt. Spektrosk., 70 (1991) 801-803

[47] A.A. Krasnovsky. Jr.. S. Yu. Egorov, O.V. Nasarova. E.I. Yartsev and G.V. Ponomarev. Photosensitized formation of singlet molecular oxygen in solutions of water soluble porphyrins. direct luminescence me:asurements. Siud. Biophys. I2\& (1988) 123-142.

[48] R. Bonnett, D.J. McGarvey, A. Harriman. E.J. Land. T.G. Truscott and U-J. Winfield, Photophysical properties of meso-tetraphenylporphyrin and some meso-tetra(hydroxyphenyl)porphyrins, Photochem. Photobiol. +8 (1988) 271-276.

[49] R. Bonnett, A. Harriman and A.N. Kozyrev. Photophysics of halogenated porphyrins, J. Chem. Soc., Furadisy Trans., 88 (1992) 763-769.

[50] B.M. Dzhagarov, G.P. Gurinovich, V.E. Novichenkov, KI. Salochiddinov, A.M. Shulga and V.A. Ganzha. Photosensitized formation of singlet oxygen and interconversion quantum yield in molecules of porphyrins and metalloporphyrins, Khim. Fiz., 6 (1987) 1069-1078. 